\title{
International Comparative Case Study of High School Students about Empathy
}

\author{
Heesun Yang1, Jung-Eun Park², Ji Hye Kim², Seong-Joo Kang ${ }^{2 *}$ \\ ${ }^{1}$ Department of Elementary Science Education, Korea National University of Education, Cheongju, South Korea \\ ${ }^{2}$ Department of Chemistry Education, Korea National University of Education, Cheongju, South Korea \\ Email: *sjkang@knue.ac.kr
}

How to cite this paper: Yang, H., Park, J.-E., Kim, J. H., \& Kang, S.-J. (2019). International Comparative Case Study of High School Students about Empathy. Psychology, 10, 148-163.

https://doi.org/10.4236/psych.2019.102013

Received: November 30, 2018

Accepted: January 29, 2019

Published: February 1, 2019

Copyright (c) 2019 by author(s) and Scientific Research Publishing Inc. This work is licensed under the Creative Commons Attribution International License (CC BY 4.0).

http://creativecommons.org/licenses/by/4.0/

(c) (i) Open Access

\begin{abstract}
In this study, we attempted to investigate the empathy ability of Korean adolescents. Davis' Interpersonal Reactivity Index was applied to 1155 high school students in Korea, and the results were compared with those obtained from the survey of the American and Dutch students with similar ages. As a result, high school students in Korea had higher cognitive empathy than other countries. But, in cognitive empathy, Fantasy (FN) was lower than Perspective Taking (PT), unlike other countries. The mean score of women in all empathy subscales was higher than that of men. And there is significant difference between humanities and natural science high school students in PT, Empathic Concern (EC) and Personal Distress (PD). However, in the comparison of mean score's effect size and correlation in the subscales of the empathetic scale, it was confirmed as an unstable structure in PD. Therefore, there is a need to educationally discuss how to improve this limitation of measuring empathy in the further research.
\end{abstract}

\section{Keywords}

Interpersonal Reactivity Index, Cognitive Empathy, Empathy for High School Student in Korea, Gender Comparison, Interdisciplinary Comparisons

\section{Introduction}

With the advent of the Fourth Industrial Revolution, there have been widespread perspectives that all things will change completely due to technological convergence (Schwab, 2016). In this regard, Schwab (2016) said that empathy, which is one of the most important parts of human nature, could be a solution to the problems caused by the loss of humanity. Empathy is a key element of human relations (Krznaric, 2014), and when we are confronted with problems, it helps 
us to solve the problems in a multidimensional way (Davis, 1980; Hoffman, 1982). Moreover recent, Programme for International Student Assessment (PISA) 2015 started to measure collaborative problem solving abilities. This means that collaborative problem solving abilities, which refers to the importance of interpersonal abilities such as empathy, are educationally needed (OECD, 2017). Empathy can be an important factor as a way to creatively and collaboratively solve the integrated and complex problems in modern society (Howe, 2012; Sawyer, 2007; Taggar, 2002). Therefore, we need to investigate educational approaches to empathy in response to these social demands.

The needs for empathy, which is a cognitive and affective response that perceives the meaning as if it is one's own, were mentioned even in the late 18th century when traditional scientific methodologies were in the mainstream (Rifkin, 2009). The study of empathy began in 1873, starting with aesthetics, and continued to grow until it exploded after Rogers (1957) in the 1950s. As a result of these interests, researchers have provided various opinions on the definitions and components of empathy (Eisenberg \& Strayer, 1987). And, most researchers agree that this is not a single concept but a compound concept that includes various characteristics and elements (Davis, 1980; Hoffman, 1982). Because of the complex nature of empathy, effects also do not appear as just one aspect, but as two or more aspects in multidimensional processes, thereby making the scale for it very important. In order to measure empathy, many criteria have been developed. In particular, the representative scales to measure empathy in terms of the general public include Davis' Interpersonal Reactivity Index (IRI), the Hogan Empathy Scale, Mehrabian and Epstein's affective Empathy Scale (Hojat et al., 2002).

The most commonly used measure to date is the IRI (Albiero et al., 2009). The IRI can measure empathic ability in terms of Perspective Taking (PT) and Fantasy (FN) in cognitive empathy, and Empathetic Concern (EC) and Personal Distress (PD) in affective empathy from the perspective of Davis (Davis, 1980). As a result of confirming previous researches applying IRI to adolescent students, this study found that, in many studies, the empathy ability was measured and analyzed according to gender and age (Davis, 1980, 1983; Davis \& Franzoi, 1991; De Corte et al., 2007; Cliffordson, 2001, 2002; Pulos, Elison, \& Lennon, 2004). In addition, the researches on empathy in elementary and middle school education have been mainly limited to the researches on school counseling (Clark, 2014), researches on educational effect according to the empathic ability of teachers and students (Boyer, 2010), researches on developing empathic ability (Hoffman, 2000) and the effect of empathy on learning (Budin, 2001). However, there has never been a case to confirm the relation between empathic ability and academic achievement through the comparison of empathic ability and there is no try to derive of the educational meaning about appropriateness empathic scale through its evaluation results.

In this regard, this study aims to identify the empathetic characteristics of 
Korean high school students with the use of Davis' IRI. Many previous studies were conducted regarding the necessity of empathy and scales of it. But there were few studies to compare empathy ability in IRI of Korean high school students with those of other countries (Woo et al., 2017). Therefore, this study seeks to analyze the realities of empathy abilities and confirms the possibility of using them in the field of education as there still remain many challenges in this regard.

- How does the IRI show the characteristics of high school students' empathy in Korea when compared with overseas cases?

- How do empathy abilities appear according to academic characteristics (humanities, natural science) in Korea?

\section{Methods}

\subsection{Participants}

In order to analyze the empathy ability of high school students, Davis' IRI was applied to 1155 students attending general high schools located in Korea in July 2017 (Table 1).

Table 1. Research subjects.

\begin{tabular}{|c|c|c|c|c|c|c|c|c|c|}
\hline \multirow{2}{*}{ Region } & \multicolumn{2}{|c|}{ Gender } & \multicolumn{3}{|c|}{ Grade } & \multicolumn{3}{|c|}{ Academic characteristics } & \multirow{2}{*}{ Total } \\
\hline & Male & Female & 1 & 2 & 3 & Common & Humanities & Natural science & \\
\hline $\mathrm{K}$ & 230 & 243 & 156 & 177 & 140 & 151 & 205 & 116 & 473 \\
\hline $\mathrm{D}$ & 682 & - & 307 & 210 & 165 & 307 & 72 & 304 & 682 \\
\hline
\end{tabular}

Note: Total $\mathrm{n}=1155$.

We selected two high schools with a middle level of learning ability. One school was a mixed-gender school with 473 students and the other was a boys' school with 682 students. This survey was conducted on high school students during class under the supervision of teachers. Only the questionnaires of the parents and the participants agreed with the research were used as research data. The results were compared with those cases where the IRI was applied to American and Dutch high school students. The data collected for comparison are taken from the results of the research in which the IRI was applied to 417 Americans aged 18 to 38 (Chrysikou \& Thompson, 2016), and 232 Dutch high school students with an average age of 17.77 (Hawk et al., 2013). Since there were few cases in which all four IRI scales were applied to multiple student samples in the same time period and even the gender difference was presented, the characteristics of countries were compared and analyzed as the most similar research data.

\subsection{Materials}

The IRI, which is the most popular empathy scale, grasps that empathy is a multi-dimensional entity and divided it into four subscales (Davis, 1980). The subscales are, namely, PT, FN, EC and PD (Table 2). 
Table 2. The Components of Davis' IRI.

\begin{tabular}{ccl}
\hline \multicolumn{2}{c}{ Dimension } & \multicolumn{1}{c}{ Contents } \\
\hline $\begin{array}{l}\text { Cognitive } \\
\text { empathy }\end{array}$ & $\begin{array}{c}\text { Perspective-Taking (PT) } \\
\text { Fantasy (FN) }\end{array}$ & $\begin{array}{l}\text { It measures the tendency to adopt viewpoints of others } \\
\text { It measures the tendency to engage in novels or movies } \\
\text { empathy }\end{array}$ \\
Empathetic Concern (EC) & $\begin{array}{l}\text { It measures the tendency of interest, compassion, and } \\
\text { warmth for others experiencing negative experiences }\end{array}$ \\
& Personal Distress (PD) & $\begin{array}{l}\text { It measures the tendency of inconvenience and anxiety } \\
\text { when seeing negative experiences of others }\end{array}$ \\
\hline
\end{tabular}

These four subscales of the IRI consist of 28 items in a 5-point Likert scale ranging from 0 to 4 points. The IRI used in this study, which is a translated version of Davis' IRI, is very similar to the items of the overseas cases used as the comparative research data. However, the reliability of these items was confirmed in order to supplement the limitations of interpretation. In this scale, the KMO value for item was $.904, \chi^{2}$ in the Bartlett sphere formation validation was $12,449.878$, and the degree of freedom $(p)$ was $378(.000)$. In addition, in terms of the reliability by subscale, the value of Cronbach' $\alpha$ for PT was .753, FN was .769 EC was .799 , and PD was .805 . These results confirmed that the measurement tools used in this study were reliable.

\subsection{Analytical Procedure}

In order to examine whether the leaner characteristics appear on the scale, gender difference in various aspects was investigated through T-test, and T-test results were analyzed according to the academic disciplines (humanities and natural science) in order to identify cognitive and affective elements in empathy abilities of high school students. The relationship between the subscales of the empathy scale was analyzed using the correlation analysis method, and the statistical analysis results presented above were compared with the results of the application of American and Dutch high school students.

\section{Results}

In order to measure the empathy ability of high school students in Korea, Davis' IRI was applied, and the results were compared with those of the United States and the Netherlands. We were focused on analysis of cognitive and affective aspects of empathy, and rediscovering the meaning of IRI by analyzing the correlation between the subscales.

The cognitive empathy ability was higher than the affective empathy ability among high school students in Korea in Table 2. The mean score of cognitive empathy was 2.59 and that of affective empathy was 2.32. However, EC was showing the highest score, and PD was found to be the lowest empathy ability among four subscales. Both of them are affective empathy factors which has large gap. This is related to the previous study that EC continue to increase in puberty and adulthood (Romer et al., 1986), but its tendency affected to reduce 
PD (Davis, 1983; Davis \& Franzoi, 1991). In this study, we wanted to directly compare the data with the US (Chrysikou \& Thompson, 2016), and the Dutch (Hawk et al., 2013). However, since the data about the US and the Dutch are presented only mean scores of the subscales, the overall mean were roughly calculated and compared as in Table 3.

Table 3. Comparison of the IRI subscales of Korean, American and Dutch high school students.

\begin{tabular}{|c|c|c|c|c|}
\hline \multirow{2}{*}{\multicolumn{2}{|c|}{ Dimension }} & \multicolumn{3}{|c|}{ Mean score (standard deviation) } \\
\hline & & Korean $^{\mathrm{a}}$ & American $^{\mathrm{b}}$ & Dutch $^{c}$ \\
\hline \multirow{2}{*}{$\begin{array}{l}\text { Cognitive } \\
\text { empathy }\end{array}$} & $\mathrm{PT}$ & $2.65(.55)$ & $2.57(.71)$ & 2.36 \\
\hline & FN & $2.53(.64)$ & $2.63(.80)$ & 2.52 \\
\hline \multirow{2}{*}{$\begin{array}{l}\text { Affective } \\
\text { empathy }\end{array}$} & $\mathrm{EC}$ & $2.70(.63)$ & $2.84(.74)$ & 2.37 \\
\hline & PD & $1.94(.63)$ & $1.69(.78)$ & 1.62 \\
\hline
\end{tabular}

Note: Perspective Taking $=$ PT; Fantasy $=$ FN; Empathetic Concern $=$ EC; Personal Distress $=$ PD. $\mathrm{n}^{\mathrm{a}}=$ $1155, \mathrm{M}$ age $\mathrm{e}^{\mathrm{a}}=17 . \mathrm{n}^{\mathrm{b}}=417, \mathrm{M}$ age $\mathrm{e}^{\mathrm{b}}=33.17 . \mathrm{n}^{\mathrm{c}}=232, \mathrm{M}$ age $\mathrm{c}^{\mathrm{c}}=17.77 .{ }^{\mathrm{C}}$ In the Dutch data, the empathy ability of the IRI is presented separately for men and women.

Based on the data in Table 3, the average cognitive empathy of American students is 2.6 and 2.44 for Dutch students. And the average affective empathy of American students is 2.27, while Dutch students are 2.00. These results confirm that the cognitive empathy ability in Korean high school students (2.59) is little lower than that of American students, and the affective empathy ability in Korean (2.32) is little higher than that in US, but both dimensions of empathy are much higher than that of Dutch students. So, it can be said that empathy ability of Korean students is similar to that of students in US, but higher than that of students in Dutch. These results are different from that of research on the comparison about the empathy ability of elementary school students among Korean, American, and Dutch (Woo et al., 2017). It showed that the cognitive empathy ability of Korean elementary school students was higher than that of American or Dutch elementary school students, whereas the affective empathy ability of Korean elementary school students is lower than that of Americans or Dutch students.

In terms of cognitive empathy, Korean high school students exhibited that PT was much higher than FN, even though high school students in other countries had a higher FN than PT. FN has been supported by educators as a useful learning tool, learning with creative properties (Egan, 1992). However, in Korea's high school curriculum, students' intelligence is assessed on the basis of having a lot of knowledge. And these students' abilities are determined based on scores. Ultimately, because this result has a major impact on university admission (Cheong, 2005), it will be difficult for students to have a variety of learning opportunities in a permissive atmosphere that will stimulate FN of high school students. And in all subscales, Korean adolescents' PT and PD were the highest in all three countries. In Korean data, a comparison of the mean scores between 
the subscales reveals that EC was the highest, followed by PT, FN and PD. In the case of the United States, that of EC was also the highest, followed by FN, PT and PD. However, In the case of the Netherland, FN was highest followed by EC, $\mathrm{PT}, \mathrm{PD}$. In other words, the common thing that can be seen in the three countries is that PD appears as the lowest level of empathy. However, there is a peculiarity point is that the highest empathic ability of Korea and the US are EC and the Netherlands is FN.

After comparing the country's empathy for each subscale, we used Hedges'g to identify the effect sizes of the values for the four subscales of Korean and American students. This is because the only way that we can confirm means and standard deviations of four subscales is the research for US data (Chrysikou \& Thompson, 2016). As a result, there was a small difference ( $\mathrm{gs}=.145-.211$ ) between two countries' empathy subscales except PD (Hedges' $g=.371,95 \%$ CI: -.356 - 1.089). This means that $\mathrm{PD}$ is unstable as an empathy scale to measure empathy ability between groups.

\subsection{Comparison of Mean Score Correlation between IRI Subscales}

The correlation between subscales was investigated to confirm the suitability of Davis' IRI. First, the results of the application to high school students in Korea showed higher correlation between cognitive empathy and affective empathy, and it can be confirmed that each scale has a positive influence on each other. In addition, the structure of the scale was confirmed through the correlation between the subscales, which was compared with the results of the American and Dutch high school students (Table 4).

Table 4. Comparison of the IRI correlation among Korean, American and Dutch high school students.

\begin{tabular}{|c|c|c|c|}
\hline \multirow{2}{*}{ Division } & \multicolumn{3}{|c|}{ Correlation } \\
\hline & Korea $^{\mathrm{a}}$ & American $^{\mathrm{b}}$ & Dutch $^{c}$ \\
\hline Cognitive empathy vs. affective empathy & $.545^{\star *}$ & - & - \\
\hline PT vs. FN & $.437^{\star *}$ & $.25^{\star * *}$ & $.302^{* * *}$ \\
\hline PT vs. EC & $.683^{* *}$ & $.66^{* * *}$ & $.515^{* * *}$ \\
\hline PT vs. PD & $-.088^{* *}$ & $-.20^{* * *}$ & $.180^{\star *}$ \\
\hline FN vs. EC & $.545^{\star *}$ & $.31^{* * *}$ & $.471^{* * *}$ \\
\hline FN vs. PD & $.167^{* *}$ & $.13^{* *}$ & $.324^{* * *}$ \\
\hline EC vs. PD & .009 & -.09 & $.394^{\star * *}$ \\
\hline
\end{tabular}

Note: Perspective Taking $=$ PT; Fantasy $=$ FN; Empathetic Concern $=$ EC; Personal Distress $=$ PD. $\mathrm{n}^{\mathrm{a}}=$ $1155, \mathrm{M}$ age ${ }^{\mathrm{a}}=17 . \mathrm{n}^{\mathrm{b}}=417, \mathrm{M}$ age $\mathrm{e}^{\mathrm{b}}=33.17 . \mathrm{n}^{\mathrm{c}}=232, \mathrm{M}$ age ${ }^{\mathrm{c}}=17.77 .{ }^{*} p<.05 .{ }^{* *} p<.01 .{ }^{* *} p<.001$.

The correlation between subscales of empathy factors among high school students in Korea showed that the correlation between PT and EC was the highest, and it showed a positive relationship. On the other hand, there was a negative correlation between PT and PD. Overall, PT and EC were highly correlated with 
other subscales, but the correlation with PD showed a negative relationship, or the correlation value became lower. Even though PD and EC are empathy abilities in terms of affective empathy, their correlation was the lowest of all.

The analysis of data from the three countries found that the correlation between EC and PT was the highest. And correlations of PT and EC, PT and FN, FN and EC, and FN and PD showed positive in common. Therefore, it can be confirmed that the correlation including the cognitive empathy ability exhibits a positive relationship to empathy. However, the difference is that the correlation between PT and PD was negative in Korea and the United States, but the data of the Netherlands was slightly positive. In addition, the relationship between PD and EC was an insufficiently positive correlation in Korea, whereas it was an insufficiently negative correlation in the United States, and its coefficients were insignificant. However, in the Netherlands, the correlation had a slight positive relationship, showing significant coefficients. Accordingly, it seemed that PD does not mean a significant relationship in the correlation with other subscales, which is similar to the results of the previous studies. Also, we found that there are some problems in the consistency of the scale. In order to compare correlations across countries, we used $\mathrm{z}$ tests. As result, most of subscale-comparisons were significant (ps from $.000-.045$ ), suggesting inconsistency between three countries according to our research.

\subsection{Differences in Empathy Abilities according to Learner's Gender}

It examined how learner characteristics are reflected in empathy abilities through the IRI. First, the results of analysis on the differences of empathy abilities according to gender are summarized in Table 5. For high school students in Korea, the mean of empathy ability of female was higher than that of male in the overall empathy ability and each subscale. In the case of male students, EC was most excellent among subscales, followed by PT, FN and PD. This tendency agreed with that of female.

Table 5. Table type styles.

\begin{tabular}{lccccccc}
\hline \multirow{2}{*}{ Dimension } & \multicolumn{6}{c}{ Mean score (standard deviation) } \\
\cline { 3 - 8 } & & \multicolumn{2}{c}{ Korea $^{\mathrm{a}}$} & \multicolumn{2}{c}{ American $^{\mathrm{b}}$} & \multicolumn{2}{c}{ Dutch $^{\mathrm{c}}$} \\
\cline { 3 - 8 } & & $\mathrm{Men}^{\mathrm{a} 1}$ & Women $^{\mathrm{a} 2}$ & Men $^{\mathrm{b} 1}$ & Women $^{\mathrm{b} 2}$ & Men $^{\mathrm{c} 1}$ & Women $^{\mathrm{c}}$ \\
\hline $\begin{array}{l}\text { Cognitive } \\
\text { empathy }\end{array}$ & PT & $2.64(.54)$ & $2.70(.58)$ & 2.46 & 2.65 & $2.20(.61)$ & $2.51(.60)$ \\
Affective & FN & $2.50(.62)$ & $2.65(.68)$ & 2.61 & 3.00 & $2.28(.52)$ & $2.76(.50)$ \\
empathy & PD & $2.68(.61)$ & $2.78(.68)$ & 2.45 & 2.75 & $2.07(.87)$ & $2.67(.75)$ \\
\hline
\end{tabular}

Note. Perspective Taking $=$ PT; Fantasy $=$ FN; Empathetic Concern $=$ EC; Personal Distress $=$ PD. $\mathrm{n}^{\mathrm{a}}=1155$ $\left(\mathrm{n}^{\mathrm{a} 1}=912, \mathrm{n}^{\mathrm{a} 2}=243\right), \mathrm{M}$ age $\mathrm{e}^{\mathrm{a}}=17 . \mathrm{n}^{\mathrm{b}}=417\left(\mathrm{n}^{\mathrm{b} 1}=171, \mathrm{n}^{\mathrm{b} 2}=246\right), \mathrm{M}$ age $\mathrm{e}^{\mathrm{b}}=33.17 . \mathrm{n}^{\mathrm{c}}=232\left(\mathrm{n}^{\mathrm{cl}}=107, \mathrm{n}^{\mathrm{c} 2}=\right.$ 125), $\mathrm{M}$ age ${ }^{\mathrm{c}}=17.77$. ${ }^{\mathrm{a}}$ In Korean data, there is a significant difference according to gender except PD. ${ }^{\mathrm{b}}$ No standard deviation is presented in the US data, but there is a significant difference according to gender. 'The Dutch data do not provide significant values according to gender. 
The commonalities among the adolescent in the above three countries include that empathy of women is superior to that of men in all respects. This is similar to the result of a study that analyzed the IRI's subscales and masculinity and femininity (Ingoglia et al., 2016), which showed that all four subscales were negatively correlated with male performance and positively correlated with female performance. Through Table 5, we tried to confirm that there are statistically significant differences in empathy abilities between male and female depending on the country. The data showed that, in the case of the United States, the statistic differences between men and women in all empathy dimensions were significant, while that of Korea showed significant difference in PT, FN and EC. As a result of analyzing the differences between men and women by subscale, in the cases of the United States and the Netherlands, the ability of FN was the best in both men and women. In the case of males in both countries, the second highest empathy was PT in the cognitive empathy factor followed by EC in affective empathy. But in the case of female students, the next best ability was EC followed by PT. This suggests that boys are, compared to girls, more likely to develop cognitive empathy than affective empathy. However, this was not found in Korean high school students. Through comparing the effect sizes of four subscales of male and female students between Korea and Dutch, it was found that there was a very large effect size difference in the comparison of the male students group of the two countries (gs $=.796-.923$ ). In the comparison of female students, the magnitude of the effect was intermediate between PT and PD (gs $=.217-.325)$. This also indicates that there is a difference in scales when using IRI to compare countries.

As shown by the IRI results, which have compared by gender and countries, PD is not sufficient to utilize as a consistent empathy subscale. For this reason, it seems that PD is not used for the measurement of empathy ability among four empathy subscales in other previous studies (Eberly-Lewis \& Coetzee, 2015; Hawk et al., 2013; Mcwhirter et al., 2002). However, a fundamental analysis of $\mathrm{PD}$ weaknesses is needed rather than this way.

\subsection{Differences in Empathy Abilities According to Learner's Discipline}

The results of the study on the differences in empathic abilities according to academic aptitude of high school students are shown in Table 6. There were many cases where Davis' IRI was analyzed according to age or gender. However, there were cases neither in the United States nor the Netherlands, in which the results of the analysis of this scale were presented according to academic aptitude. Therefore, this study intended to analyze IRI only in terms of the data from Korean high school students. According to the Korean high school curriculum system, Korean high students are supposed to choose one of the two courses for the purpose of their career advancement in the second year of high school. One of the two choices is the humanities and the other is the natural science. In this context, humanities students refer to the students who want to 
enter the careers in the humanities and social sciences, and natural science students refer to the students who want to enter careers in mathematics, science and engineering.

Table 6. Difference in disciplines of empathy abilities among high school students in Korea.

\begin{tabular}{lcccc}
\hline \multirow{2}{*}{ Dimension } & & \multicolumn{2}{c}{ Mean (standard deviation) } & \multicolumn{1}{c}{ T-test result $(p)$} \\
\cline { 3 - 4 } & & Humanities $^{\mathrm{a}}$ & Natural science & \\
\hline \multirow{2}{*}{ Overall empathy ability } & $2.42(.45)$ & $2.45(.40)$ & $-.978(.329)$ \\
& total & $2.54(.54)$ & $2.60(.47)$ & $-1.539(.124)$ \\
Cognitive empathy & PT & $2.56(.57)$ & $2.67(.52)$ & $-2.629(.009)^{* *}$ \\
& FN & $2.52(.61)$ & $2.53(.61)$ & $-.209(.834)$ \\
& total & $2.30(.57)$ & $2.67(.52)$ & $-.115(.908)$ \\
Affective empathy & EC & $2.58(.67)$ & $2.70(.57)$ & $-2.548(.011)^{*}$ \\
& PD & $2.02(.55)$ & $1.90(.64)$ & $2.469(.014)^{*}$ \\
\hline
\end{tabular}

Note. Perspective Taking $=$ PT; Fantasy $=$ FN; Empathetic Concern $=$ EC; Personal Distress $=$ PD. $\mathrm{n}^{\mathrm{a}}=277$, $\mathrm{n}^{\mathrm{b}}=420 .{ }^{*} p<.05,{ }^{* *} p<.01$.

Among affective empathy abilities, natural science students are superior in all aspects except PD. Based on previous studies (NGSS Lead States, 2013; Cheryan et al., 2013), we hypothesized that the cognitive empathy abilities are high in natural science high school students and affective empathy abilities are high in humanities students, but the results were different from our expectations. The mean of the two groups was similar and it did not make any significant difference in overall empathy. There was no statistical difference in cognitive and affective aspects when separating the overall empathy into two aspects. However, the differences in the two groups can be identified by separating empathy into four subscales. A significant difference between groups was seen in PT, EC and PD factors, but FN was not. In the case of natural science students, EC was highest among subscales, followed by PT, FN and PD. This tendency agreed with that of humanities students. This is similar to the results of a comparison of Korean high school students' empathy by gender which we refer before in previous section (Table 5).

\section{Discussion}

There has been some concern about dehumanization centered on computers and robots by artificial intelligence with the advent of the Fourth Industrial Revolution (Schwab, 2016). Therefore, as scientific technology and industry develop, education for human beings should be strengthened to increase emotional abilities such as empathy and care (Cooper, 2004; Krznaric, 2014; Hatcher et al., 1994). However, it is doubtful about the educational effects of empathy education in modern society because there was no investigation into the actual realities of empathy levels among students in Korea for educational applications. 
Therefore, in this study, the empathy ability of Korean high school students was measured using Davis' IRI in terms of cognitive and affective aspects, and the results were compared with the results from overseas cases.

For this study, the questionnaire survey was conducted by applying Davis' IRI to 1155 students in general high school in Korea, and the results were compared with those of the American and Dutch high school students with similar ages. In order to compare the results with the same measurement tool, a set of items adapted from Davis' IRI were used, and the items were found to be very reliable (.753 -.805). We present our findings in three parts, corresponding to the research questions driving our study, such as the cognitive and affective empathy abilities of learners, gender differences, and interdisciplinary comparisons.

First, we confirmed whether Davis' IRI reflected the learner's cognitive and affective characteristics. Korean students were superior to students in other countries in their affective empathy abilities, but Korean students were little lower than US in terms of cognitive empathy. In the results of analysis in elementary school students in Korea (Woo et al., 2017), their cognitive empathy ability was higher than their affective empathy ability. But in the high school case, the situation was different. In our participants' cognitive empathy ability, PT showed a higher mean score than that of high school students in other countries, but the mean value of the FN scale was lower in Korea than in the United States. Based on the results of the previous studies which showed that cognitive empathy has a significant positive correlation with academic achievement (Austin et al., 2005), We could draw conclusions that especially PT is related to cognitive abilities such as reasoning (Eisenberg \& Strayer, 1987), intelligence quotient (IQ) (Davis, 1983) and, another intelligence (Jolliffe \& Farrington, 2004). The fact that PT ability of Korean students is higher than that of American and Dutch students seems to be associated with the fact that Korean high school students show the higher average than the OECD in the Programme for International Student Assessment (PISA, 2017). However, it is necessary to consider that FN of Korean students is lower than that of students in the United States. This phenomenon is no surprise in the Korean high school curriculum, which is oriented toward logical thinking regarding (Cheong, 2005). High school curriculum should be able to stimulate imagination based on knowledge (Egan, 1992). However, the results of this study show that the curriculum of Korea high school has a limitation. Since university admissions are the ultimate goal of high school education in Korea, it is impossible to apply the curriculum beyond this. However, current college admission is determined by the score about students' knowledge. Due to these effects, although high school students' PT is high, their FN seems to have low results in cognitive empathy. Since FN is a deeper cognitive empathy process that scientifically reasons the other's inner state (Barak et al., 1987; Erera, 1997), further research is required to improve this part of empathy ability.

Second, we examined whether gender differences exist in empathy ability. 
Female students in Korea were superior to male students in all areas of the empathy scale. This is a global trend commonly found and suggests that gender is related to the development of empathy in adolescence and young adulthood. Empirical evidence that female adolescents begin to be more empathetic than male adolescents is found in junior high school (Eisenberg et al., 1991), high school (Davis \& Franzoi, 1991), and college students (Davis, 1980). However, what has been found in this study is that the PD of Korean adolescents do not show significant differences depending on their gender, unlike other countries (Chrysikou \& Thompson, 2016; Hawk et al., 2013). This means that gender differences in PD may or may not be significant from country to country. In addition, we could also confirm this PD's instability in the result of the correlation and comparisons of means in subcomponents among countries. After all, this is means that PD scale needs to be revised to reflect the empathy characteristics of personal pain as the threshold for this scale.

Third, the relationship between academic aptitude and empathy ability of humanities and natural science high school students was investigated in terms of empathy ability. The natural science high school students showed higher empathy ability in the overall empathy area except PD. The Next Generation Science Standards (NGSS Lead States, 2013) highlighted the social co-operation ability of scientists and engineers, because it is required for STEM-related students who have relatively limited interpersonal skills and this ability (Cheryan et al., 2013). Therefore, it would be meaningful that Korean students of natural high school have excellent PT, EC and PD. However, especially FN was the only area that showed insignificant differences between the two groups, although it was expected that the biggest difference should be FN according to differential academic disciplines (Egan, 1992). This indicates that there is a limit to this scale because it fails to identify differences between groups according to academic characteristics in terms of FN. There were some previous studies conducted by regarding subject using empathy. A previous study on school science using empathy only talked about the importance of empathy in classroom situations (Arghode et al., 2013). In this context, the other researchers used IRI to demonstrate the effectiveness of education in science class (Guney \& Seker, 2012). However, based on our findings, it is doubtful whether the outcome has emerged as an appropriate empathy for the subject.

Lastly, the suitability of this scale was confirmed by analyzing the correlation between the IRI's subscales. As in the case of overseas cases, cognitive empathy factors (PT and FN) were positively related to EC with high correlation coefficients. Thus, it can be said that cognitive elements play an important role in empathy. In the case of the correlation between subscales, PT and EC showed the highest correlation, followed by EC and FN. This means that EC has a great influence in empathy factors. For this reason, there were many cases where only EC was used to measure empathy ability in previous studies (Hatcher et al., 1994; Mcwhirter et al., 2002). However, PD and EC, which are empathy abilities 
of the same affective area, showed a low correlation. This suggests that there are problems with both elements. Also, it was confirmed that FN maintains a positive relationship with PT, EC and PD in the results of this study and those of previous research. This is because although $\mathrm{FN}$ is cognitive empathy ability, it has an emotional element according to Hawk (2013). However, it can be said that the FN of the cognitive aspect plays an important bridge in cognitive and affective elements in terms of empathy. However, since there were many cases in which the above subscales were excluded from the evaluation in the previous studies (Eberly-Lewis \& Coetzee, 2015; Mcwhirter et al., 2002) more detailed research needs to be conducted in this respect.

It is important to analyze empathy ability through all the elements of IRI to identify the multidimensional nature of empathy. In this regard, this study has its significance in that empathy ability was classified into cognitive and affective aspects and analyzed according to learner characteristics, and the suitability of the scale was confirmed through the analysis of the correlation between the subscales using four factors in IRI. There were many previous studies to investigate differences in empathy abilities according to age or gender (Davis \& Franzoi, 1991; Eisenberg et al., 1991) or analyze the correlation between subscales (Davis, 1980, 1983; Davis \& Franzoi, 1991; De Corte et al., 2007; Cliffordson, 2001, 2002), but there was no research to analyze empathy factors according to variables such as learners' academic aptitude. In addition, this study is meaningful in that the suitability of the scale was confirmed through the correlation between subscales of empathy and the characteristics of variables, and the Korean cases were compared with the US and the Dutch cases with similar ages. Finally, the results of this study confirmed that high school students in Korea have a lack of FN among cognitive empathy abilities compared to the American students, and the IRI scale has its limitations as an empathy scale that reflects PD and academic characteristics through actual data analysis results.

However, this study has the following limitations: First, empathy is a complex and diverse disposition that varies depending on personal characteristics, surrounding environment and individual circumstances (Hoffman, 2000), and therefore the results presented in this study cannot provide the definite cause. In this regard, this study attempted to analyze the cause from various variables and empathy aspects and present the results through a comparison with the American and Dutch cases as well as the previous studies. Second, the range of participants was limited. Multiple samples of 1155 high school students were utilized in this study. However, since some of the subjects of this study were extracted from male high school, the results may be analyzed with one-sided bias in terms of academic aptitude and gender. Finally, in cases where the four subscales of the IRI were applied when the data from the US and the Netherlands were extracted, the age group of the data from the US was different from that of the data from that of the research data of this study. However, in order to complement this, we tried to generalize the findings by comparing the data with the data of the Neth- 
erlands and analyzing the results of the previous studies.

In order to complement the results derived from this study and reflect them in future work, the IRI should be designed by extracting samples from different age groups and reflecting regional differences, and the results should be used to develop an empathy scale that reflects the gender differences and academic characteristics of Korean students through academic research and a mutual agreement among experts. In addition, the developed scale needs to overcome the limitations of Davis' IRI, and thus more clearly present the affective empathy abilities of subjects. Finally, it is necessary to extract empathy factors that are most necessary for students through the research results and develop them into educational methods so that this study will become the cornerstone of empathy-based educational activities.

\section{Conclusion}

This is the first study to analyze the empathy ability of high school students according to gender, country and academic aptitude by applying all the scales of Davis' IRI. According to the results of this analysis, IRI showed similar pattern depending on gender, but it was confirmed that there is a difference according to countries. In the comparison of empathic ability according to academic aptitude, the natural sciences students of Korea showed high empathy ability. Also, it is confirmed once again that the PD scale is incomplete, suggesting that it needs to be supplemented. However, based on the analysis of empathy scale except for the $\mathrm{PD}$, we were able to infer the problems of Korean students' high school curriculum and to seek a complementary measure for the development of empathy scale.

\section{Conflicts of Interest}

The authors declare no conflicts of interest regarding the publication of this paper.

\section{References}

Albiero, P., Matricardi, G., Speltri, D., \& Toso, D. (2009). The Assessment of Empathy in Adolescence: A Contribution to the Italian Validation of the "Basic Empathy Scale". Journal of Adolescence, 32, 393-408. https://doi.org/10.1016/j.adolescence.2008.01.001

Arghode, V., Yalvac, B., \& Liew, J. (2013). Teacher Empathy and Science Education: A Collective Case Study. Eurasia Journal of Mathematics, Science \& Technology Education, 9, 89-99.

Austin, E. J., Saklofske, D. H., \& Egan, V. (2005). Personality, Well-Being and Health Correlates of Trait Emotional Intelligence. Personality and Individual Differences, 38, 547-558. https://doi.org/10.1016/j.paid.2004.05.009

Barak, A., Engle, C., Katzir, L., \& Fisher, W. A. (1987). Increasing the Level of Empathic Understanding by Means of a Game. Simulation \& Games, 18, 458-470. https://doi.org/10.1177/0037550087184002

Boyer, W. (2010). Empathy Development in Teacher Candidates. Early Childhood Education Journal, 38, 313-321. https://doi.org/10.1007/s10643-010-0419-8 
Budin, M. L. (2001). Tea and Empathy. School Library Journal, 47, 45-46.

Cheong, J. (2005). American Universities' Ways of Selecting the Students and the Analysis of Their Implications. Journal of Education Evaluation, 18, 149-171.

Cheryan, S., Plaut, V. C., Handron, C., \& Hudson, L. (2013). The Stereotypical Computer Scientist: Gendered Media Representations as a Barrier to Inclusion for Women. Sex Roles, 69, 58-71. https://doi.org/10.1007/s11199-013-0296-x

Chrysikou, E. G., \& Thompson, W. J. (2016). Assessing Cognitive and Affective Empathy through the Interpersonal Reactivity Index: An Argument Against a Two-Factor Model. Assessment, 23, 769-777. https://doi.org/10.1177/1073191115599055

Clark, A. J. (2014). Empathy in Counselling and Psychotherapy: Perspectives and Practices. New York: Routledge.

Cliffordson, C. (2001). Parent's Judgments and Students' Self-Judgments of Empathy: The Structure of Empathy and Agreement of Judgment Based on the Interpersonal Reactivity Index (IRI). European Journal of Psychological Assessment, 17, 36-47. https://doi.org/10.1027//1015-5759.17.1.36

Cliffordson, C. (2002). The Hierarchical Structure of Empathy: Dimensional Organization and Relations to Social Functioning. Scandinavian Journal of Psychology, 43, 49-59. https://doi.org/10.1111/1467-9450.00268

Cooper, B. (2004). Empathy, Interaction and Caring: Teachers' Roles in a Constrained Environment. Pastoral Care in Education, 22, No. 3. https://doi.org/10.1111/j.0264-3944.2004.00299.x

Davis, M. H. (1980). A Multidimensional Approach to Individual Differences in Empathy. JSAS Catalog of Selected Documents in Psychology, 10, 85.

Davis, M. H. (1983). Measuring Individual Differences in Empathy: Evidence for a Multidimensional Approach. Journal of Personality and Social Psychology, 44, 113-126. https://doi.org/10.1037/0022-3514.44.1.113

Davis, M. H., \& Franzoi, S. L. (1991). Stability and Change in Adolescent Self-Consciousness and Empathy. Journal of Research in Personality, 25, 70-87. https://doi.org/10.1016/0092-6566(91)90006-C

De Corte, K., Buysse, A., Verhofstadt, L. L., Roeyers, H., Ponnet, K., \& Davis, M. H. (2007). Measuring Empathic Tendencies: Reliability and Validity of the Dutch Version of the Interpersonal Reactivity Index. Psychologica Belgica, 47, 235-260. https://doi.org/10.5334/pb-47-4-235

Eberly-Lewis, M. B., \& Coetzee, T. M. (2015). Dimensionality in Adolescent Prosocial Tendencies: Individual Differences in Serving Others versus Serving the Self. Personality and Individual Differences, 82, 1-6. https://doi.org/10.1016/j.paid.2015.02.032

Egan, K. (1992). Imagination in Teaching and Learning: The Middle School Years. Chicago, IL: University of Chicago Press.

Eisenberg, N., \& Strayer, J. (1987). Critical Issues in the Study of Empathy.

Eisenberg, N., Miller, P. A., Shell, R., McNalley, S., \& Shea, C. (1991). Prosocial Development in Adolescence: A Longitudinal Study. Developmental Psychology, 27, 849. https://doi.org/10.1037/0012-1649.27.5.849

Erera, P. I. (1997). Empathy Training for Helping Professionals: Model and Evaluation. Journal of Social Work Education, 33, 245-260. https://doi.org/10.1080/10437797.1997.10778868

Guney, B. G., \& Seker, H. (2012). The Use of History of Science as a Cultural Tool to Promote Students' Empathy with the Culture of Science. Educational Sciences: Theory and Practice, 12, 533-539. 
Hatcher, S. L., Nadeau, M. S., Walsh, L. K., Reynolds, M., Galea, J., \& Marz, K. (1994). The Teaching of Empathy for High School and College Students: Testing Rogerian Methods with the Interpersonal Reactivity Index. Adolescence, 29, 961.

Hawk, S. T., Keijsers, L., Branje, S. J. T., Van Der Graaff, J., De Wied, M., \& Meeus, W. (2013). Examining the Interpersonal Reactivity Index (IRI) among Early and Late Adolescents and Their Mothers. Journal of Personality Assessment, 95, 96-106. https://doi.org/10.1080/00223891.2012.696080

Hoffman, M. L. (1982). Development of Prosocial Motivation: Empathy and Guilt. In N. Eisenberg (Ed.), The Development of Prosocial Behaviour (pp. 281-313). New York: Academic Press. https://doi.org/10.1016/B978-0-12-234980-5.50016-X

Hoffman, M. L. (2000). Empathy and Moral Development: Implications for Caring and Justice. New York: Cambridge University Press. https://doi.org/10.1017/CBO9780511805851

Hojat, M., Gonnella, J. S., Nasca, T. J., Mangione, S., Vergare, M., \& Magee, M. (2002). Physician Empathy: Definition, Components, Measurement and Relationship to Gender and Speciality. American Journal of Psychiatry, 159, 1563-1569. https://doi.org/10.1176/appi.ajp.159.9.1563

Howe, D. (2012). Empathy: What It Is and Why It Matters. London: Palgrave Macmillan.

Ingoglia, S., Lo Coco, A., \& Albiero, P. (2016). Development of a Brief Form of the Interpersonal Reactivity Index (B-IRI). Journal of Personality Assessment, 98, 461-471. https://doi.org/10.1080/00223891.2016.1149858

Jolliffe, D., \& Farrington, D. P. (2004). Empathy and Offending: A Systematic Review and Meta-Analysis. Aggression and Violent Behavior, 9, 441-476. https://doi.org/10.1016/j.avb.2003.03.001

Krznaric, R. (2014). Empathy: A Handbook for Revolution. Random House.

NGSS Lead States (2013). Next Generation Science Standards: For States, by States.

Mcwhirter, B. T., Besett-Alesch, T. M., Horibata, J., \& Gat, I. (2002). Loneliness in High Risk Adolescents: The Role of Coping, Self-Esteem, and Empathy. Journal of Youth Studies, 5, 69-84. https://doi.org/10.1080/13676260120111779

OECD (2017). PISA 2015 Assessment and Analytical Framework: Science, Reading, Mathematics, Financial Literacy and Collaborative Problem Solving. Paris: OECD Publishing. https://doi.org/10.1787/9789264281820-en

Pulos, S., Elison, J., \& Lennon, R. (2004). The Hierarchical Structure of the Interpersonal Reactivity Index. Social Behaviour and Personality, 32, 355-359. https://doi.org/10.2224/sbp.2004.32.4.355

Rifkin, J. (2009). The Empathic Civilization: The Race to Global Consciousness in a World in Crisis Penguin (Lee, K.). Seoul: Mineumsa.

Rogers, C. R. (1957). Empathy: An Unappreciated Way of Being. The Counselling Psychologist, 5, 2-10. https://doi.org/10.1177/001100007500500202

Romer, D., Gruder, C. L., \& Lizzadro, T. (1986). A Person-Situation Approach to Altruistic Behaviour. Journal of Personality and Social Psychology, 51, 1001. https://doi.org/10.1037/0022-3514.51.5.1001

Sawyer, R. K. (2007). Group Genius: The Creative Power of Collaboration. New York: Basic Books Press.

Schwab, K. (2016). The Fourth Industrial Revolution: What It Means, How to Respond. Paper Presented at World Economic Forum Annual Meeting 2016.

Taggar, S. (2002). Individual Creativity and Group Ability to Utilize Individual Creative 
Resources: A Multilevel Model. Academy of Management Journal, 45, 315-330.

Woo, Y., Yoon, J., \& Kang, S. J. (2017). Empathy as an Element of Promoting the Manifestation of Group Creativity and Survey on Empathic Ability of Korean Elementary School Students. Eurasia Journal of Mathematics, Science and Technology Education, 13, 3849-3867. https://doi.org/10.12973/eurasia.2017.00761a 